\title{
Health care professionals' pain narratives in hospitalized children's medical records. Part 1: Pain descriptors
}

\author{
Judy Rashotte RN PhD ${ }^{1}$, Geraldine Coburn RN MN², Denise Harrison RN PhD ${ }^{1,3}$, Bonnie J Stevens RN PhD FCAHS², \\ Janet Yamada RN PhD², Laura K Abbott MSc²; the CIHR Team in Children's Pain
}

\begin{abstract}
J Rashotte, G Coburn, D Harrison, BJ Stevens, J Yamada, LK Abbott; the CIHR Team in Children's Pain. Health care professionals' pain narratives in hospitalized children's medical records. Part 1: Pain descriptors. Pain Res Manag 2013;18(5):e75-e83.
\end{abstract}

BACKGROUND: Although documentation of children's pain by health care professionals is frequently undertaken, few studies have explored the nature of the language used to describe pain in the medical records of hospitalized children.

OBJECTIVES: To describe health care professionals' use of written language related to the quality and quantity of pain experienced by hospitalized children.

METHODS: Free-text pain narratives documented during a $24 \mathrm{~h}$ period were collected from the medical records of 3822 children ( 0 to 18 years of age) hospitalized on 32 inpatient units in eight Canadian pediatric hospitals. A qualitative descriptive exploration using a content analysis approach was used.

RESULTS: Pain narratives were documented a total of 5390 times in 1518 of the 3822 children's medical records (40\%). Overall, word choices represented objective and subjective descriptors. Two major categories were identified, with their respective subcategories of word indicators and associated cues: indicators of pain, including behavioural (eg, vocal, motor, facial and activities cues), affective and physiological cues, and children's descriptors; and word qualifiers, including intensity, comparator and temporal qualifiers.

CONCLUSIONS: The richness and complexity of vocabulary used by clinicians to document children's pain lend support to the concept that the word 'pain' is a label that represents a myriad of different experiences. There is potential to refine pediatric pain assessment measures to be inclusive of other cues used to identify children's pain. The results enhance the discussion concerning the development of standardized nomenclature. Further research is warranted to determine whether there is congruence in interpretation across time, place and individuals.

Key Words: Children; Documentation; Intensity; Narratives; Pain; Words

A litiona though documentation of children's pain by health care professionals is frequently undertaken (1), the nature of narrative documentation - described as free-text notations - has not been fully investigated. Studies have primarily examined the presence and frequency of documented pain assessments in hospitalized infants and children (1-5) as well as the frequency of use of pain measurement tools in practice (6-8). Research examining words used by clinicians to communicate aspects of children's pain assessment is limited; a review of the literature revealed only one study that reported on the examination of nurses' comments about children's pain postappendectomy (9).

Recently, von Baeyer (10) recommended that clinicians treating children complement self-report with observation and knowledge of the context. The use of pain narratives with or without the use of a

\section{L'exposé narratif de la douleur par des professionnels de la santé dans les dossiers médicaux d'enfants hospitalisés. Partie 1 : les descripteurs de la douleur}

\begin{abstract}
HISTORIQUE : Même si les professionnels de la santé consignent souvent en dossier la douleur des enfants, peu d'études portent sur la nature des termes utilisés pour décrire la douleur dans les dossiers médicaux des enfants hospitalisés.

OBJECTIFS : Décrire l'utilisation de la langue écrite par les professionnels de la santé au sujet de la douleur subie par les enfants hospitalisés, tant sur le plan de la qualité que de la quantité.

MÉTHODOLOGIE : Les chercheurs ont colligé les exposés narratifs libres consignés sur une période de 24 heures dans les dossiers médicaux de 3822 enfants (de 0 à 18 ans) hospitalisés dans 32 unités de patients hospitalisés de huit hôpitaux pédiatriques canadiens. Ils ont procédé à une exploration descriptive qualitative par une approche d'analyse de contenu.

RÉSULTATS : Les chercheurs ont colligé des exposés narratifs sur la douleur 5390 fois dans 1518 de 3822 dossiers médicaux d'enfants (40\%). Dans l'ensemble, les choix de mots représentaient des descripteurs objectifs et subjectifs. Les chercheurs ont repéré deux grandes catégories, comportant leurs sous-catégories respectives d'indicateurs de mots et d'indices connexes : indicateurs de douleur, y compris les indices comportementaux (p. ex., indice vocal, moteur, facial et d'activité) et indices affectifs et physiologiques, et qualificateurs des termes, y compris les qualificatifs d'intensité, de comparaison et temporels.

CONCLUSIONS : La richesse et la complexité des termes qu'utilisent les cliniciens pour consigner la douleur des enfants appuient le concept selon lequel le terme "douleur » est une étiquette qui représente une myriade d'expériences différentes. Il serait possible de préciser les mesures d'évaluation de la douleur en pédiatrie pour inclure d'autres indices utilisés pour dépister la douleur chez l'enfant. Les résultats enrichissent la discussion sur l'élaboration d'une nomenclature standardisée. D'autres recherches s'imposent pour déterminer si l'interprétation est congruente dans le temps, selon les lieux et selon les individus.
\end{abstract}

validated pain intensity measurement tool may be health care professionals' way of addressing what Franck and Bruce (6) referred to as the reductionism and oversimplification that is inherent in documenting pain only in terms of pain intensity. In response to these gaps in the research and views about the limitations of pain measurement scales, an analytic expansion beyond the quantitative examination of the nature and frequency of pain assessment practices was undertaken. The specific objectives of the exploration were: to qualitatively describe the narratives related to children's acute pain as documented by nurses, physicians and other health professionals; to identify and categorize the instances of a particular type of pain narrative; and to uncover the multidimensionality of their vocabulary to communicate information about the child's pain status. Our findings are presented in two articles. The present article (Part 1) provides an overview of the 
study design and a description of the words recorded by clinicians to describe hospitalized children's acute pain as perceived by the care provider, child or parent. The second article (Part 2), published in the present issue of Pain Research $\mathcal{E}$ Management (pages e84-e93), concerns the first two study objectives, with detail about how these words are structured within the narrative.

\section{METHOD}

A qualitative descriptive exploration using a content analysis approach was used. The exploration was nested within the large program of research by Stevens et al (1) (The Canadian Institutes of Health Research [CIHR] Team in Children's Pain (CTP-79854), 2006-2011 www.childrenspainstudy.ca) that evaluated the effectiveness of a multidimensional knowledge translation strategy to improve pain assessment, pain management and clinical outcomes.

\section{Sample}

All pain narratives collected from children's charts and entered into the centralized web-based Canadian Pediatric Pain Research (CPPR) database comprised the data set for this exploration. The database consisted of information on painful procedures, pain assessments and pain management interventions. The method for this overall chart data extraction has been described elsewhere (11). Following ethics approval from the research ethics boards at eight participating pediatric Canadian hospitals, the data were collected from the charts of infants and children $\leq 18$ years of age who were hospitalized on four inpatient units per hospital (14 medical, eight surgical, 10 critical care units) for longer than $24 \mathrm{~h}$. Pain data from the $24 \mathrm{~h}$ period (midnight to midnight) closest to the time of data collection were collected from the charts of the first 30 consecutively admitted children (per unit) over four consecutive four- to six-week periods between October 2007 and April 2008, for a total of 120 charts/unit or 3840 charts in total.

All research nurses received rigorous training on the electronic data collection procedures and the study protocol. Using a 'yes' or 'no' checkbox format, research nurses were asked on the CPPR Database Form to indicate the presence of: a nursing note referring to the patient's pain; a physician's note referring to the patient's pain; a note where it clearly reflected a patient's self-report of pain; a note appearing on a patient's flow sheet referring to his or her pain; and a note indicating pain assessment with no description of where the note came from or who wrote it. A free-text notation was considered a 'pain narrative' if it contained any word found within the predetermined list of variables housed in the subsections of the CPPR database form (ie, child pharmacological interventions, child physical interventions, child psychological interventions and child pain assessment data). A free-text box was also available for research nurses to provide additional evidence of pain assessment and management as noted in free-text notations. The text entered at the one institution whose medical charting was conducted in French was translated into English by the bilingual research nurse, the translation of which was verified by the site's coinvestigator before being entered into the database.

\section{Data collection}

All pain narratives from the CPPR database in an Excel format (Microsoft Corporation, USA) were retrieved as an entire group and as five collated groups: professional designation (ie, nurse, physician and non-specified); age of child (ie, $\leq 12$ months, one to three years, four to five years, six to 12 years and 13 to 18 years); clinical setting (ie, medical, surgical and critical care units comprising pediatric and neonatal critical care units); hospital site (deidentified); and occurrence with use or nonuse of a validated pain assessment tool. The first and second authors checked all narratives for accuracy of spelling for the sole purpose of accurate word finds and counts and to search for missing data.

\section{Data analysis}

The narrative text was analyzed using a conventional content analysis approach (12) guided by procedures described by Mayring (13) and
Sandelowski (14). The coding process was initiated with what Miller and Crabtree (15) refer to as a template analysis technique. An openended template was derived from the Pain Assessment PQRST (Provocation/Palliation, Quality/Quantity, Region/Radiation, Severity, Timing/Type of onset) Checklist $(16,17)$ because operational definitions for each of these initial descriptive coding categories could be easily created from the definitions and questions embedded in the checklist. It was also assumed that these standard components of initial and ongoing pain assessments - which are embedded in various pain assessment tools - may be embedded in health care professionals' documentation. Similarly, the McGill Pain Questionnaire (MPQ) (18) served as a template when analyzing the patients' self-reported words that were recorded in the narratives because the MPQ has been validated for adolescents and it is known that some clinicians use it for assessing pain in that group.

As part of the first level of analysis, the first two authors initially coded 500 narrative texts independently using the PQRST Checklist and the MPQ and then compared coding to ensure that the codes were being consistently applied. It is a key tenant of content analysis that the researcher be open to new emerging codes after encountering the text and to revise the coding scheme as necessary as well as to validate or disprove previous assumptions. Therefore, the PQRST template was revised and expanded as new codes were revealed in the text (eg, intervention and outcome of interventions). The MPQ template was also modified when children's words did not fit with this scheme (eg, rhythmic, localization). Every narrative was then analyzed using the expanded coding scheme by three coders (JR, GC, DH). Coder consistency was verified at biweekly face-to-face meetings. During the second level of analysis, six members of the CIHR Team in Children's Pain (JR, GC, DH, BS, LA, JY) used an inductive process of interpreting the narrative text, in which they moved systematically from the whole to parts and back to the whole again. The group met to discuss new ways of assessing the data sets, collectively examine the data to develop relational configurations between the various data sets and build consensus related to the emerging findings. The initial codes were subsequently integrated into an overarching framework that reflected the content of the entire narrative (ie, assessment, planning, intervention and evaluation), which is presented in Part 2. All narratives were then reviewed again using this final framework to ensure fitting representation. Memos written throughout the analysis process became part of the data analysis and were incorporated into the findings.

For the purpose of exploring word usage (19), a count (ie, manifest content analysis) was performed when appropriate to confirm regularity in the data or a pattern usage (ie, latent analysis) that had been revealed and described. Alternative word usage and an examination of the contexts (ie, hospital sites, clinical units, age groups) within which the various words were used were also explored.

As suggested by Leininger (20), evaluation criteria (credibility, confirmability, transferability, meaning-in-context, saturation, recurrent patterning) were used to ensure the qualitative data were analyzed in a rigorous fashion. All categories and concepts were firmly grounded in the data by identifying the text from which they were derived. Excerpts from the narrative text were used to provide illustration, which further ensured a good fit between the data and analytical results. In addition to multiple coders (21), other plausible ways of organizing the data were explored. An audit trail of coding decisions and data analysis procedures as well as copies of evolving coding schemes were maintained. Finally, various members of the CIHR Team in Children's Pain reviewed the codes and categories against a random selection of narratives. Two nurses, both having more than five years of pediatric clinical experience and qualitative research experience, reviewed all narratives to ensure that the final schema had been consistently applied and held that the coding scheme was logically consistent with their personal experience of pain documentation; ie, there was ecological validity (19). 
TABLE 1

Narratives by selected subgroups

\begin{tabular}{lc}
\hline Narrative date set subgroups & $\begin{array}{c}\text { Number of narratives per } \\
\text { subgroup ( } \mathbf{n}=\mathbf{5 2 8 3})\end{array}$ \\
\hline Age & 1365 \\
$0-12$ months & 622 \\
$1-3$ years & 404 \\
$4-5$ years & 1482 \\
$6-12$ years & 1410 \\
13-18 years & \\
Health care professional & 1873 \\
Nurse & 355 \\
Physician & 3055 \\
Not specified & \\
Unit type & 1828 \\
Medical & 1782 \\
Surgical & 1673 \\
Critical care & \\
Use of validated pain assessment tool & 1669 \\
Yes & 3614 \\
No &
\end{tabular}

\section{RESULTS}

Of the 3840 children's medical records, 18 were excluded due to missing demographic data and for not meeting the inclusion criteria, reducing the final sample to 3822 . Within this sample, 1518 of 3822 $(40 \%)$ contained one or more pain narratives for a total of 5390 narratives. A total of 1006 of 3822 (26\%) children had a documented pain assessment at least once within the $24 \mathrm{~h}$ period of the study using pain narrative alone, and 512 of $3822(13 \%)$ had a narrative combined with a pain assessment measure (1). Of the 5390 pain narratives collected, in 107 instances, the research nurse wrote a comment that a narrative was noted in the medical record rather than providing the actual narrative's text, such as "descriptive words provided" or "narrative notation present". This reduced the total number of narratives that could be analyzed to 5283 (refer to Table 1 for total number of narratives per subgroup).

The word 'pain' was noted in 2014 of 5283 (38\%) narratives while the word 'discomfort' was used in 224 of 5283 (4\%). Both words were used to indicate the presence of pain (eg, "apparent discomfort"; "appears in pain") and its absence (eg, "appears free from pain"; "no discomfort"). The two words appeared to be used synonymously (eg, "Morphine given for discomfort; effective for a short while but the pain returns"), although a difference in meaning appeared to be discernable in a small number ( 56 of $5283 ; 1 \%$ ) of narratives (eg, "mild epigastric discomfort but no complaints of pain"). There was an exponential increase in the use of these two words related to the child's age. For example, of the 2014 narratives in which the word 'pain' was used, 391 of those $(19 \%)$ were in the narratives of children $\leq 5$ years of age, while $1623(81 \%)$ were in the narratives of school age and adolescent age groups. A difference in word use did not appear to be associated with the use or nonuse of a validated tool, level of pain intensity score (eg, "pain currently 3/10"; "indicates 3/10 discomfort") or causal factors (eg, postoperative or procedural events, hunger). There were some differences in the frequency of the use of the term based on unit, with critical care units using the word 'pain' 235 of 1673 times (14\% of narratives) and 'discomfort' 32 of 1673 times (2\%) compared with surgical units ( 863 of $1782 ; 48 \%$ for 'pain' and 76 of $1782 ; 4 \%$ for 'discomfort') and medical units (916 of 1828 [50\%] for 'pain' and 116 of 1828 [6\%] for 'discomfort').

Health care professionals used specific words to note discrete types of pain. The term 'myalgia' was used once (ie, "had myalgia in lower extremities and pain to biopsy site") for identifying muscle pain. 'Headache' was documented in 167 of 5283 (3\%) narratives across all age groups, although $>50 \%$ of these were noted in children $\geq 6$ years of

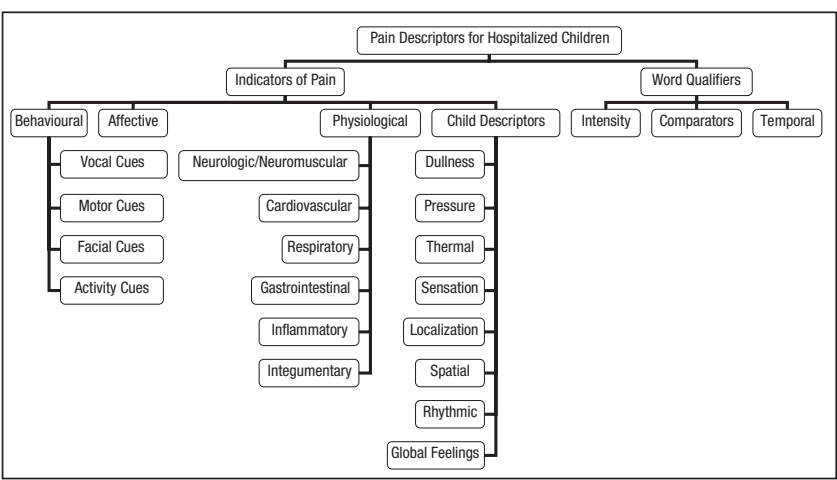

Figure 1) Classification of words used by health care professionals to describe children's pain

age. The word 'headache' was also documented by all clinicians across all unit types, although only $16 \%$ (26 of 167 ) were noted in the critical care narratives, while the word's use was equally divided between the surgical and medical units (42\%). The words 'tender' and 'sore' were used in 48 of $5283(1 \%)$ and 58 of $5283(1 \%)$ narratives, respectively. The word 'tender' implied a negative sensitivity to touch, most often in relation to the localization of pain or discomfort and to denote some form of negative reaction elicited when a specific area of the body was touched or palpated. The word 'sore' was used as a synonym for 'tender' (eg, 'sore to touch') only twice. Sometimes, clinicians used the words 'sore' and 'tender' interchangeably; other times, the words were used to represent different qualities of pain (eg, "tender to touch but sore all over"). The word 'distress' was noted in 182 of 5283 (3\%) narratives. Frequently, clinicians used the word 'distress' in conjunction with other descriptors to clarify the intent of the word choice (eg, "in acute distress, paroxysmal coughing"; "no distress, comfortable, not irritable").

Two major categories regarding the words used by clinicians to record the nature of the child's pain emerged: indicators of pain and word qualifiers. The indicators of pain category represents a particular grouping of mutually exclusive substantive or discrete cues such as gestures, actions, sounds or signs, and were both objective and subjective. Objective indicators were further sorted into three subcategories of word descriptors: behavioural, affective and physiological, with their corresponding cues. Child descriptors (ie, subjective indicators) were comprised of the words that clinicians reported that children used to describe their pain. At least one indicator of pain was noted in $47 \%$ (2485 of 5283 ) of the narratives, with little difference noted between nurses and physicians. The number of pain indicators recorded per narrative was as follows, with nurses and physicians demonstrating a similar pattern in usage: one indicator $=1667$ of $5283(33 \%)$; two indicators $=645$ of $5283(12 \%)$; three indicators $=$ 142 of $5283(3 \%)$; and $\geq 4$ indicators $=31$ of $5283(1 \%)$. The word qualifier category represents the adjectives and adverbs used by clinicians to express a sense of quality to the child's pain by imparting a sense of limitations, or lack thereof. Figure 1 provides an overview of the classifications of word use.

The indicators of pain and word qualifiers were used within the narrative in two ways. One use was to reflect a pain assessment either with or without a declaration of pain (eg, "some pain in shoulder; crying, not wanting to settle") or its absence (eg, "states has no pain, looks happy"). A second use was to evaluate the effectiveness or noneffectiveness of a pain management intervention such as a pharmacological intervention (eg, "morphine decreased, patient now moving around and arching off of bed"), physical intervention (eg, "settled with bundling") or psychological intervention (eg, "encouraged to deep breath and cough, well controlled during procedure"). There were no differences noted in words used by health care professionals to describe the quality and pain intensity of pain for the purposes of describing the results of a pain assessment or to report the evaluation of any type intervention. 


\section{INDICATORS OF PAIN}

Behavioural indicators

Four distinct and qualitatively different subgroups of words within behavioural indicators were used by health care professionals. These subgroups represented vocal, motor, facial and activity cues. Behavioural indicators were used throughout the narratives by all clinicians, although physicians documented more activity cues than other behavioural, affective or physiological indicators of pain, while nurses across all types of units recorded all types of pain indicators, with or without the use of a validated pain tool.

Vocal cues: Words used by all clinicians to document children's vocalizations were classified as high-energy, low-energy and pleasure sounds. Words describing both high- and low-energy sounds indicated the presence of pain. High-energy sounds, which were defined as sounds characterized by continuous or bursts of increased energy requirements, often incorporating a change in respiratory pattern, and producing deep, loud or forceful sounds, included such words as 'cry'/'crying', 'screaming' and 'grunting'. Words to describe sounds that were more plaintive and subdued in nature were classified as low-energy sounds and revealed varying levels of pitch. Examples of low-energy, high-pitched sounds included 'squeak'/'squeaky' and 'whine'/'whining'. Examples of low-energy, lowpitched sounds included 'moan', 'groan' and 'whimper'. Words that clinicians used to document their perception that a child was free of pain were classified as pleasure sounds. The words used were age-specific such as 'babbling' and 'cooing' for infants, and 'giggling' and 'laughing' for the other age groups. Pleasure sound cues were rarely noted.

Motor cues: Words used by all clinicians to document the child's motor movements were classified into three subgroups: self-defensive movements, self-comforting movements and nonpurposeful movements. Selfdefensive movements were purposeful, assertive in nature and focused on active, outward actions against a perceived threat (eg, 'biting'). Words included within self-comforting movements were those that were passive, inward-directed and required less motor movement and energy expenditure (eg, 'guarding'). Words included within nonpurposeful movements were those that described a generalized bodily motor response and were associated with states of agitation (eg, 'squirming') or repose (eg, 'settled').

Self-defensive movements: arching, biting, clenching fist, fighting, fingers clawing at mouth, flexing, grabbing, head turning, hitting, kicking, pinching, pushing away, resistant to turning, rolling around, turning head (from side to side/back and forth).

Self-comforting movements: chewing on hand (used only in the 0 to $<12$ months of age group), drawing legs up, favouring, fetal position, guarding, immobile, limited moving, pulling away, withdrawing.

Nonpurposeful movements: agitated, combative, fidgety, fussy/fussing, restless, squirming, stiffening, straining, thrashing, tossing and turning, unsettled, wriggling, writhing.

'Restless', 'fussy' and 'unsettled'/'not settled' were frequently used to describe infants' state of agitation. 'Settled', rather than 'resting', was the most common word used by all clinicians (393 times) to indicate a state of repose and was most commonly used with children $\leq 3$ years of age (319 of 393 [81\%]).

Facial cues: Words used by all clinicians to document the facial indicators of the presence or absence of pain included anatomical and emotive cues. Anatomical cues were related to some form of facial muscular movement (ie, brow bulge, eye squeezing, clenching teeth, wrinkled brow, smiling). Emotive cues referred to an impression intuited from the look in the child's eyes or face. Examples included such words as 'tearful', 'watchful' and 'frantic-looking', which indicated the presence of pain, while 'bright and alert' indicated the absence of pain.

Activity cues: This group of words focused on the child's ability to participate in activities of daily living: sleeping, mobilizing, eating and drinking, and being engaged. Sleeping, which refers to the normal function of sleep for restorative purposes, included the words 'slept'/'sleeping' and 'naps'/'napping'. Mobilizing, which referred to the child's ability to engage in ambulation activities, included the words 'unable to weight bear', 'unable to hold head up', and 'able to touch toes and hop from wheelchair to bed'. Eating and drinking, which referred to the normal functions associated with nutritional intake, included the words 'inability to swallow', 'refused to eat', and 'bottled eagerly'. 'Playing', 'up in mom's arms', 'cuddling', 'interacting with parent', 'watching TV', and 'talkative' were the words classified as being engaged, which referred to the child's ability to engage in social activities or to interact with their surroundings.

\section{Affective indicators}

The words in this subcategory were used by health care professionals as a way to capture their general impression of the child's mental or physical disposition, ie, to depict the mood or emotional state of being as one means of determining the presence or absence of pain. Nurses used these words more frequently than physicians (207 of 1873 [11\%] versus 14 of 355 [4\%], respectively).

Affective indicators of pain: anxious, cranky, grumpy, fatigued, inconsolable, irritable, mad, miserable, not usual self, uncomfortable, uneasy, unhappy, upset.

Affective indicators of absence of pain: acting normal self, calm, comfortable, content, consolable, cooperative, good spirits, happy, peaceful, playful, relaxed, (looks) well.

The word 'tolerate' and its derivatives (ie, 'tolerated', 'tolerating'), as in 'well tolerated' or 'not tolerating', was used 187 times, across all sites, units, age groups and narrative sources. The word was always noted as an outcome to a procedure (eg, 'tolerated IV start'), activity (eg, 'not tolerating handling'; 'tolerated cuddling'), intervention (eg, 'tolerated wean to morphine') or pain event (eg, 'tolerated the pain'). Clinicians, for the most part, provided pain indicators when the phrase 'not well tolerated' was used, whereas the phrase 'well tolerated' was noted to stand alone.

\section{Physiological indicators}

In this subcategory, the words (or phrases) used were cues that were associated with the involuntary physiological responses that can be numerically captured (eg, via cardiorespiratory monitors), measured and objectively assessed through the senses, such as through touch (eg, 'hot', 'distended', 'firm') or sight (eg, 'shivering'). Words were coded within six body system subgroups:

Neurological/neuromuscular system: confused, drowsy, (face) flushed, jerky, jittery, jumpy, no response to painful stimuli, shaking, shivering, spasms, startles, sweating, withdrawal of limbs to painful stimulation.

Cardiovascular system: blood pressure, heart rate, tachycardia.

Respiratory system: breathing heavy, coughing, difficulty breathing, hyperventilating, oxygen desaturations, respiratory rate, increased secretions, shortness of breath, tachypneic.

Gastrointestinal system: cramping, distended, firm, gagging, gassy, hard, nausea, retching, soft, vomiting.

Inflammatory system: erythematous, febrile, hot, irritation, itching/ itchy, pruritus, swelling/swollen, taut.

Integumentary system: excoriated, peeling skin, red/redness and pink.

Some physiological indicators noted in the narratives were common to all participating pediatric units, while others were specific to critical care contexts (ie, 'negative pressure increased', 'increased intracranial pressure' and 'peak inspiratory pressures increasing') but these were rarely documented. Physiological indicators were combined with other indicators (eg, "shaking, moaning, increased heart rate, not settling"). No patterns were noted across sites, age groups or narrative sources.

\section{Child descriptors}

Health care professionals documented the words used by children and youth to describe their pain and indicate the characteristic or quality of their pain. Only one narrative documented the use of a metaphor used by the child to describe the pain (ie, 'like a big pinch'). Eight subgroups were identified within this subcategory:

Dullness: ache (head, stomach or tummy ache), heaviness, hurts, sore. Pressure: compressed, cramping, pinch, pressure-like, pulling, tender, tense. 
TABLE 2

\section{Word qualifiers used by health care professionals in pain} narratives

\begin{tabular}{ll}
\hline Category & Words documented \\
\hline Intensity & Acceptable, acute, adequate, bad, big, bit, borderline, \\
& comfortable/comfortably, controlled, easily, extremely, fairly, \\
& free (eg, pain free), good, hard (eg, hard night), huge, large, \\
& little, lots/ a lot, lots to medium, loudly (eg, cries loudly), \\
& manageable, medium, mild/mildly, minimum/minimal, minor, \\
& moderate/moderately, more, much, nicely (eg, settles nicely), \\
& no, non (eg, non-tender), none, none to little, normal, not \\
& (eg, not any, not really, not very much; not much; not \\
& optimal, not too great), okay, peacefully, poor/poorly, quite \\
& (eg, quite well), quietly, really (eg, really sore), rough, \\
& sensitive, severe, significant, slight/slightly, small, small to \\
& medium, some/somewhat, sort of (eg, sort of there; sort of \\
& spasming), tender, tense, that much, tolerable (eg, pain \\
& tolerable), too (eg, too sore), unbearable, unmanageable, \\
& very (eg, very happy, very agitated), vigorously/vigorous, \\
& well (eg, well controlled, well managed), +/++/+++ \\
Better, calmer, decreased/decreasing, easier, happier, \\
improved/improving/ no improvement, increased/ \\
increasingly, less, more, never experienced that much pain \\
before, not as (eg, not as bad), reduced, relatively (eg, \\
relatively calm as compared to yesterday), same, still, \\
subsided/subsiding, unchanged, worse \\
Always, at times, briefly, consistently, constant/constantly, \\
every once in a while, every so often, frequently, intermittent/ \\
intermittently, mostly, now and then, occasional/occasionally/ \\
on occasion, off and on, persistent, quickly, sometimes, \\
waxes and wanes \\
Temporal \\
Comparator
\end{tabular}

Thermal: burning/burns, heartburn, hot, searing.

Sensation: numb/numbness, photosensitivity, stinging, tingling.

Localization: bobo, ouchie, painful.

Spatial: shooting.

Rhythmic: stabbing, throbbing.

Global feelings: dizziness, feeling bad, owww.

Although the word 'painful' could be a descriptor for a general pain state, clinicians always provided information on the pain's location when children used this word (eg, "states that saline lock in R arm is painful"; "L leg extremely edematous and states painful to touch"). Therefore, the word within this context was designated as a localization word.

\section{WORD QUALIFIERS}

Qualifiers are defined as words or phrases that restrict or modify the meaning of another word or phrase. In this case, adjectives and adverbs were used in the narratives to modify the objective and subjective manifestations or qualities of the child's pain. They were often evaluative in nature and conveyed a subjective overall level of tolerability and intensity of the pain experience from the observer's or the child's perspective. Three subcategories of word qualifiers were identified: intensity, comparator and temporal. Table 2 provides the list of words in each subcategory.

\section{Intensity qualifiers}

Qualifying adjectives were used to describe the severity and amount of pain. Sometimes, these adjectives were associated with the behavioural or affective pain indicators they had identified (eg, 'loud cry'). They used qualifying adverbs in a similar fashion (eg, 'crying vigorously'). Clinicians also used qualifying adjectives and adverbs to convey their perception that the child did not have pain (eg, 'very happy'; 'settles easily'; 'sleeping peacefully'; 'resting comfortably'). At times, they further explicated the intensity of pain they perceived the child was experiencing by using additional adjectives and adverbs (eg, "very

$\begin{array}{cccc}\stackrel{ }{*} & & \\ 0 & \text { little } & \text { medium } & \text { big } \\ \text { no } & \text { slight } & & \text { lots } \\ \text { none } & \text { little bit } & & \text { a lot } \\ & \text { minimum } & \text { large } \\ & \text { minor } & & \text { huge } \\ & + & ++ & +++\end{array}$

Figure 2) Qualifying adjectives of pain intensity

loud cry'). Some adjectives conveyed an evaluation of the tolerability of the pain experience, such as "pain not controlled", "pain tolerable", "adequate pain control", "pain seems well controlled", "appears to be in an unbearable amount of pain". A continuum of qualifying adjectives was evident, another example of the evaluative nature of qualifiers (Figure 2). The symbol $+/++/+++$ was used in $3 \%$ of narratives (160 of 5283) by all clinicians across all unit types at all institutions and was most frequently used in narratives of children $<3$ years of age. Sometime, use of these symbols and adverbs (eg, 'very') communicated a sense of urgency around observed behaviours and a need for immediate intervention. These narratives reported an action taken (eg, "pt +++ fussy and irritable, chloral hydrate given with good effect"; “appears very uncomfortable, can't settle, morphine bolus given”).

When clinicians' documented the child's words in their narratives, it was noted that children also used adjectives and adverbs to express the intensity of their pain (eg, "complains of really bad hurt", "complains of big headache", "describes pain as hurting a lot". A child's expression of pain tolerability (eg, "states that discomfort in foot tolerable", "acceptable pain level of 6") occurred in narratives of children $\geq 6$ years of age.

\section{Comparator qualifiers}

Comparator qualifiers explicitly or implicitly indicated that the child's pain had an attribute of more, less or the same manifestation of intensity than it did at some previous point in time. The use of the past tense of verbs as adjectives (eg, 'increased pain now'; 'decreased discomfort'; 'calmed now') or the use of a present participle (eg, 'increasing pain') acted in this capacity. Adjectives, such as 'worse', 'better', 'more' and 'less', also served as a form of comparison of the intensity or quantity of pain either based on the behavioural or affective pain indicators they had identified (eg, 'looking better'; 'more restless'; 'less agitated'; 'happier') or the child's self-reports ("states pain is subsiding"; "states pain is the same, not better or worse"; "states still somewhat uncomfortable"; "complains of worse headache"). Clinicians also qualified a comparator word to further explicate their perception of the child's pain (eg, 'somewhat better'; 'much improved').

\section{Temporal qualifiers}

Temporal qualifiers were words used to qualify the pain in terms of duration, presence or absence in and through time, and rate of recurrence. For example, adverbs (eg, 'always', 'consistently') and adjectives (eg, 'persistent', 'constant') were used to convey the continual or unremitting nature of either the child's pain (eg, "patient says she is always in pain") or indicators of pain (eg, 'persistent restlessness'; 'irritation sensation constantly'). Similarly, adverbs (eg, 'intermittently' or 'briefly') and phrases (eg, 'at times' or 'waxes and wanes') were used to report the transitory or short-lived nature of the child's pain (eg, 'intermittent headache') or indicators of pain's presence or absence (eg, 'intermittent moan'). The use of the word 'not' with adverbs or adjectives also conveyed this same sense (eg, 'headache not persistent'). Words or phrases such as 'frequently', 'occasionally' or 'every once in a while' were used to describe the rate of recurrence of behavioural and affective pain indicators (eg, "crying frequently"; "up frequently overnight"; "patient settled with occasional screaming noted"; 
"child crying occasionally due to headache and intermittent abdominal discomfort") or by school age children or youth to describe their pain (eg, "states has occasional abdominal cramps").

\section{DISCUSSION}

To date, research related to the assessment of children's pain has primarily examined pain intensity scores from a quantitative perspective. Less attention has been devoted to analysis of the qualitative data from medical records; however, substantial portions of the patients' records are descriptive, narrative and qualitative in nature. This qualitative descriptive exploration of health care professionals' pain narratives has revealed that regardless of whether they use a validated pain intensity measurement tool, electronic record or a specific pain scoring documentation tool, clinicians use narratives extensively to declare the presence or absence of pain and to describe the child's pain.

The word 'pain' was the most commonly documented word by all clinicians when referring to the child's pain experience, with an exponential increase in use with increasingly older age groups. One possible explanation for this finding is that with cognitive maturation (22-24) and increased awareness of the concept of pain through various social media genres, children themselves use the word 'pain' to describe this subjective phenomenon or, alternatively, provide more discriminating cues that are specific to their pain experience thus increasing clinicians' confidence that the elicited behaviour truly represents the presence or absence of pain.

For the most part, clinicians appeared to use the word 'discomfort' as a synonym for 'pain'. The pain indicators and qualifiers they used to record the nature of the child's experience in conjunction with the word 'discomfort' did not appear to be different from those documented when the word 'pain' was recorded. However, in a small number of narratives, the word 'discomfort' was used to distinguish the child's negative sensation as different from that of 'pain', yet a difference in meaning between these two words was not explicitly revealed. The reader of the narrative is left to interpret the meanings of the two words. For example, are 'pain' and 'discomfort' evaluative words that convey the clinicians' judgment about the intensity of the child's pain experience? Does the use of the word 'pain' imply that the negative sensation has reached the point at which tolerance has been pushed beyond what is bearable, while 'discomfort' is a less intense sensation that may not require treatment? In their seminal research related to the MPQ, Melzack and Torgerson (25) used the word 'discomforting' as a relatively low scoring intensity word ( 2 on a scale of 1 to 5 ) when asking adult patients, physicians and psychology students to determine pain intensities implied by a variety of words that described the qualities of pain. Do health care professionals use the word 'discomfort' with this meaning in mind? Does the word 'discomfort' have the same meaning for children at various maturational stages as it does for an adult, and do children interpret a difference when they are asked by a health care professional if they experience discomfort or pain?

Norvell et al (26) reported a difference in assigned meaning of pain intensity when nurses and physicians were asked to place such terms as 'pain', 'ache' and 'hurt' on a pain intensity scoring tool, with the word 'pain' having the highest intensity value. However, a significant difference occurred between nurses and physicians in the placement of these terms on the intensity tool. Individual and group differences in perceptions about the meaning of these words exist. The International Association for the Study of Pain Task Force on Taxonomy (27) offers no guidance on how to distinguish between these words, nor does the recent 2011 update (www.iasppain.org/AM/Template.cfm?Section=Pain_Definitions). Therefore, further research is warranted in this area because lack of common understanding as to the meaning of these words as they are used by children experiencing acute pain and by the clinicians caring for them can have implications when making decisions about when and how to treat the child's pain. For example, it has been reported that 'discomfort' is regarded as a condition for which pain medication is either unwarranted or managed with nonopioids or nonpharmacological strategies, whereas 'pain' is regarded as warranting treatment with opioids (28).
It is unclear why the words 'pain' and 'discomfort' were found less frequently in critical care unit narratives compared with medical and surgical units. It may relate to the clinicians' confidence in making a definitive diagnosis of pain in nonverbal children, of whom there are more in these units. Yet, infants and children who were ventilated - and thus in critical care units - had pain assessed with a validated pain assessment measure more frequently than those who were not ventilated (1). Therefore, one would assume that clinicians would have greater confidence in making a pain diagnosis when using a validated pain tool. An alternative rationale is that there may be community of practice norms that influence the use of these words within the critical care context. More studies using qualitative research techniques, such as think-aloud sessions, interviews and observations, are warranted to understand when and how these terms are used in various contexts.

A wide variety of words across all clinicians' narratives were found to describe the indicators they used to determine the presence, quality and intensity of pain. Narratives revealed that clinicians frequently used a combination of behavioural, affective and physiological indicators, revealing the richness and multidimensionality of their vocabulary when documenting children's pain. Narratives that contained physiological indicators, particularly vital signs, were found to be composites of various other indicators of pain presence. Perhaps this is because the validity of physiological indicators, particularly vital signs, as an indicator of pain has been questioned (29). Instead, it may indicate clinicians' need to communicate the process of interpreting the child's signs and symptoms as pain versus some other patient problem and justification for a particular intervention. The number of pain indicators that they recorded in a narrative ranged from zero to four or more. Does an increase in the number of pain indicators documented indicate that the clinician perceives a greater intensity of pain or is it simply the number of cues the child presented? How does the reader of this information perceive the information when more or less cues are documented? From another perspective, could the documentation of multiple indicators represent a cluster of cues that relate to a specific type of pain or discomfort? For example, high-pitched cry, eye squeezing and stiffening is a cluster of behavioural indicators that are associated with the presence of neurological pain.

Similar to the wide variety of words to label pain, some word descriptors are undoubtedly synonyms; others appear to be synonymous but may vary in quality and intensity. This attempt to further classify the major category of word choices into subgroups may appear to be an excessive level of discrimination. However, because many of the words provide subtle differences or nuances despite their similarities, they may be important to clinicians who are attempting to communicate the many dimensions of their perceptions of the child's pain, thus demonstrating the complexity and multidimensional nature of pain. As a point of illustration, it was impossible to determine whether the terms 'fussy', 'agitated', 'restless' and 'unsettled' were used interchangeably or if different meanings were attached to them. We chose to group them as nonpurposeful motor cue movements because both the literature $(28,30)$ and our own expert clinical experience informed us that body movement was often inherent in the description that clinicians used to describe these words. However, 'fussy' has been noted to be used synonymously with 'crying' in the literature (31) or noncry sounds (32) and perhaps should also have also been classified as a vocal cue. Similarly, the word 'irritable' has been used to suggest a disturbed sleep pattern in infants (33) and a change in temperament or mood, especially in older children (23). Therefore, this word could be an affective indicator as well as a behavioural one. Broome and Tanzillo (34) reported that the term 'irritable'/'irritability' was regarded by some neonatal nurses as a state of arousal caused by nonpain sensations such as hypoxemia, yet Jones (35) indicated that it was a sign of pain in neonates. Similarly, the word 'agitated' may have various but similar meanings to that of the word 'irritable'. More research that explores the potentially multiple and contradictory connotations of each word as used by clinicians and family caregivers is warranted because it has also been reported that interpretation of these terms is 
associated with treatment management (28). In addition, research in this area is mostly related to the neonatal population and was published more than 20 years ago. Clinicians' communication and charting conventions may have changed over the past two decades.

When clinicians were dependent on objective indicators as their sole source of evidence when assessing children's pain (ie, when children were unable to verbalize their pain), they used many of the cues that align with the various pain intensity measures developed for nonverbal children. For example, they documented many of the facial, motor, vocal and consolability cues found in pain assessment tools such as the Children's Hospital of Eastern Ontario Pain Scale (36), the CRIES (Crying, Requires oxygen, Increased vital signs, Expression, Sleep) scale (37) or the FLACC (Face, Legs, Activity, Cry, Consolability) scale (38). This finding is not surprising because many of the measures were initially developed using clinical experts to establish consensus on indicators of pain in various pediatric patient populations (39) or extensive literature reviews, which were subsequently validated in the clinical setting (40). It is also important to note that clinicians wrote narratives in the negative form (eg, 'no facial grimacing') using the same objective pain indicators as evidence for absence of pain. This form of narrative appears to indicate that a pain assessment was conducted and provided justification for pain management activities.

The language used to describe children's pain is multidimensional and rich. Some words (eg, 'fussiness', 'restless', 'settled', 'unsettled', 'comfortable') were frequently used, while many others were used infrequently. It could be interpreted that the wide array of words is indicative of a lack of precision and an absence of a standardized nomenclature. A call for standardization is a direct imperative from this interpretation. Conversely, the extensive selection of words revealed in the data could be used to enhance the lexicon of pain words, which would enrich communication about pain in the pediatric population. Different questions are at the heart of these interpretations. For example, does limited use of many of these words mean that they are considered insignificant and irrelevant to the situation and thus should be ignored and discarded at the time of documentation? Alternatively, does the use of a few common words by many reflect the limits of clinicians' vocabulary to describe the ineffable, a lack of specificity in describing the child's pain experience by the majority of clinicians, and/or a lack of attention to or awareness of the differences in children's pain experiences? This extensive selection of words, even if only used occasionally, may signify a multitude of different, unique pain events characterized by different qualities and suggests that it is time to look more closely at the difficulty that clinicians have in communicating pain before children's pain experiences are reduced to a standardized set of words that will marginalize each child's particular experience.

It is essential that the discussion about pain vocabulary and the definitions of words used to convey the child's pain experience (ie, quality and intensity of pain) happen sooner rather than later because the universal employment of electronic health records (EHRs) is imminent. EHRs do not simply transfer free-text notes into an electronic format; they capture clinical information with structured vocabularies, with constrained choices in the form of drop-down lists, check-boxes and other data entry devices. When using a standardized vocabulary, the clinician is forced to select predetermined words (eg, a list of those pain indicators that are associated with particular pain measurement tools). Consequently, they may be forced to use a word that does not fit the particular context, thus misleading users of the information; to use a text box for entering a free-text section of the clinical note, which, due to time constraints, are infrequently accessed; or to not bother to chart the information because they interpret the lack of an adequate word choice to mean that it has been determined to be unimportant (41).

All health care professionals use a wide variety of natural health care-related jargon and insider language (eg, 'well tolerated') and descriptive qualifying adjectives and symbols (eg, +/++/+++; 'little', 'lots') in their pain narratives. Although these word qualifiers are not as precise as a numerical value generated from pain intensity scoring tools, their extensive use in pain narratives demonstrates that clinicians have developed an impressive and extensive language to give voice to their patients' pain. These words are recognized as being ambiguous but they also have context-dependent meanings to health care in general, specific patient populations and the particular patient. Each pain narrative is meant to be interpreted in light of the patients' diagnosis, interventions received, other oral and written communications, and an appreciation for the local community of practice. As noted by Wenger (42), local and global communities of practice create a shared repertoire of medical symbols and words that take on specific usages, which includes the discourse by which members create shared meaningful statements that can be interpreted similarly. They also serve to express complex meanings without lengthy written discussion because clinicians need to communicate efficiently. For example, it may be possible that all health care professionals apply a commonly accepted numerical value to the words they use (eg, $0=$ none, $1=$ mild, 2 = moderate, or $3=$ severe) as has historically been used in studies asking patients to rate their pain (43). Further study is warranted on the various meanings of these words as used by health care professionals to understand whether some of this vagueness or ambiguity that is associated with certain word choices serves as a deference strategy because they are uncertain as to the nature of the pain, particularly when there are contradictory cues or the child is nonverbal, or as a way to downgrade the intensity of the child's pain experience based on their beliefs about how severe the pain should be for particular procedures or diagnoses. Research using qualitative methodologies is recommended since meanings need to be revealed in light of the sociocultural contexts in which their use is embedded.

The number of pain intensity descriptors and word qualifiers that children used, as reported by health care professionals, appears relatively limited. Because it was not the intention in the present study to investigate the words used by children, it is impossible to know whether children used additional words that were not documented by health care professionals, or whether children's word choices were limited as a result of the numbers and types of pain with which they had previous experience or level of language socialization skills. The word choices that children used and then were incorporated into health care professional narratives also described the nature (ie, feeling or sensation) and intensity of the pain. Health care professionals' narratives demonstrated that there was a wider variety of pain descriptors used by older children, a finding similar to studies that investigated the language most commonly used by children $(24,44)$. This finding is logical becayse cognitive development and increased language socialization play an important part in a child's ability to describe pain effectively $(23,45)$.

Words used to cue clinicians as to the presence and intensity of a child's pain as found in their free-text notations have been brought together and categorized. This qualitative descriptive exploration of health care professionals' pediatric pain narratives builds on the work of other researchers who have identified lists of pain indicators $(25,39,46,47)$. These efforts are not meant to be definitive, but are only one attempt to develop new approaches to the problem of describing children's pain. This type of work must always begin with the development of the range and scope of the descriptive words used to describe pain by clinicians, parents and children. More work is needed in this area; the list not only needs to be expanded but an attempt to link them to procedural events and the creation of word definitions is needed. This work also has the potential to refine pediatric pain assessment measures to be more inclusive of other cues that clinicians use to assess for children's pain, all of which can potentially assist clinicians, particularly novices, to better identify pain and communicate it to others in a meaningful way. Health care professionals' use of pain indicators in their pain narratives, particularly when they are augmented by word qualifiers, may help clinicians make decisions about pain management when it is difficult to differentiate the clinical significance of a single point pain score. Consider an eight-year-old who reports a pain intensity score of 3 of 10 as documented on the pain flow sheet. What is the meaning of this score? However, the narrative communicates that the child is "++ 
restless, crying, and rigid with movement." This information helps others to understand that the health care professional judged the score of 3 as one requiring a pharmacological intervention when taking into account the behavioural cues exhibited. Therefore, other clinicians will better understand the meaning of a score of 3 of 10 for this particular child. In other words, these findings add to the argument that pain intensity scores cannot be the only and definitive source of information (48). Finally, with the conversion to EHRs, the development of the content of pain documentation will necessitate a fuller understanding of the language used by clinicians. EHRs are currently being developed and implemented at multiple sites all over the world and a number of systems are routinely used. The data retrieved from this and other pain narratives can help software developers enhance the list of lexicons that are built into these systems.

\section{Limitations}

There are several limitations to the present study. First, using a retrospective chart review provides no opportunity to clarify meaning of the narratives with the authors of the texts. However, this method emulates clinical review of the medical record and the interpretations accorded to the text by the multiple clinicians who access them on a daily basis. Second, it is likely that many clinicians provided more than one narrative each, and the same and multiple clinicians would have commented on the same child. Because this information was not collected, the sampling of comments may over-represent certain health care professionals or certain patients. Similarly, the data collection method prohibited us from examining for statistically or clinically significant differences between health care professional groups, units and age groups. However, the purpose of the present exploration was to provide a description of pain narratives and identify the patterns of word usage; therefore, analysis using inferential statistics was not suitable for this qualitative method. Finally, the textual data were rendered de-contextualized in relation to the patient's situation because the narratives were not collected with regard to time of notation, sequential charting entries or relationship to pharmacological and nonpharmacological interventions, specific procedural event and diagnosis. For example, each pain narrative could not be cross-referenced to a particular procedure or diagnosis to examine potential relationships with the clinicians' word choices. Lack of a broader context (with narratives sequentially documented over time in relation to other events) prevented an interpretive analysis of emerging themes from these data. However, due to the large number of narratives retrieved across Canada from different hospitals and patient care units, the results are, nonetheless, valuable within these limitations.

\section{Concluding remarks}

The present study has revealed professional practice that was not hitherto obvious. Now that it has been rendered visible, discussion can follow as to whether these word choices are desirable features of clinicians' documentation, perhaps by relating them to subsequent patient outcomes and, if so, how these words can be refined and improved so that there is congruence in interpretation across time, place and individuals. Pain narratives were analyzed to reveal the richness and

\section{REFERENCES}

1. Stevens B, Harrison D, Rashotte J, et al. Pain assessment and intensity in hospitalized children in Canada. J Pain 2012;13:857-65.

2. Gharavi B, Schott C, Nelle M, Reiter G, Linderkamp O. Pain management and the effect of guidelines in neonatal units in Austria, Germany and Switzerland. Pediatr Int 2007;49:652-8.

3. Harrison D. Pain assessment and procedure pain management. J Pediatr Child Health 2006;42:6-9.

4. Taylor EM, Boyer K, Campbell FA. Pain in hospitalized children: A prospective cross-sectional survey of pain prevalence, intensity, assessment and management in a Canadian pediatric teaching hospital. Pain Res Manag 2008;13:25-32.

5. Twycross A. Children's nurses' post-operative pain management practices: An observational study. Int J Nurs Stud 2007;44:869-81. multidimensionality of vocabulary used by health care professionals to document children's pain. The information explicated from the pain narratives enables clinicians to elaborate the quantitative pain intensity analysis, providing richer detail, which potentially assists them to initiate new lines of thinking through attention to surprises or paradoxes, thus providing fresh insights. The many indicators of pain used by health care professionals documenting their assessments and qualifiers to describe the quality and intensity of the child's pain lend support to the concept that the word 'pain' is a label that represents a myriad of different pain experiences. There is broad scope for further investigation into the words that clinicians use in pain narratives that would have potential for generating guidelines for best pain documentation practice beyond pain intensity. It is possible that understanding clinicians' use of particular words related to the child's pain can help make vocabularies more internally consistent. Further research is needed to link patients' validated scores to the descriptors used in their narratives. There is also a need to explore the relationship between clusters of behavioural cues and their association with specific types pain or discomfort to assist clinicians with their interpretation of the child's pain experience.

\section{SUMMARY}

Documentation of children's pain is frequently completed with use of free-text notations; however, few published studies have explored their nature. In the present study, the words recorded by health care professionals to describe hospitalized children's acute pain were examined. The results have the potential to refine pediatric pain assessment measures to be inclusive of other cues used to identify children's pain and can enhance the discussion concerning the development of standardized nomenclature. With the conversion to EHRs, a fuller understanding of pain documentation is warranted to better enable software developers to enhance lexicons that are built into these systems.

SOURCES OF SUPPORT: Funding was provided by the Canadian Institutes of Health Research (CIHR) (CTP-79854 and MOP-86605).

CIHR MEMBERS: In addition to the six authors of this article, the CIHR Team in Children's Pain consists of the following members: Melanie Barwick, Fiona Campbell, Christine Chambers, Janice Cohen, Greta Cummings, Carole A Estabrooks, G Allen Finley, Celeste Johnston, Margot Latimer, Shoo Lee, Sylvia LeMay, Patrick McGrath, Christina Rosmus, Doris Sawatzky-Dickson, Shannon D Scott, Souraya Sidani, Jennifer Stinson, Robyn Stremler, Anne Synnes, Anna Taddio, Edith Villeneuve, Fay Warnock and Andrew R Willan.

ACKNOWLEDGEMENTS: The authors gratefully acknowledge the contributions of Tricia Kavanagh, a coinvestigator on the CIHR Team in Children's Pain; the research nurses who assisted with data acquisition at the participating hospitals; the Centre for Computational Biology at The Hospital for Sick Children for creating, housing and supporting the database; Jasna Grujic-Ciric for assistance with data management; and Margot Thomas for assistance with data analysis and manuscript preparation.

6. Franck LS, Bruce E. Putting pain assessment into practice: Why is it so painful? Pain Res Manag 2009;14:13-20.

7. Harrison D, Loughnan P, Manias E, Johnston L. Utilization of analgesics, sedatives, and pain scores in infants with a prolonged hospitalization: A prospective descriptive cohort study. Int J Nurs Stud 2009;46:624-32.

8. Shrestha-Ranjit JM, Manias E. Pain assessment and management practices in children following surgery of the lower limb. J Clin Nurs 2010;19:118-28.

9. Salantera S, Lauri S, Salmi TT, Aantaa R. Nursing activities and outcomes of care in the assessment, management, and documentation of children's pain. J Pediatr Nurs 1999;14:408-15. 
10. von Baeyer CL. Children's self-report of pain intensity: What we know, where we are headed. Pain Res Manag 2009;14:39-45.

11. Stevens BJ, Abbott LK, Yamada J, et al. Epidemiology and management of painful procedures in children in Canadian hospitals. CMAJ 2011;183:E403-10.

12. Hsieh H-F, Shannon SE. Three approaches to qualitative content analysis. Qual Health Res 2005;15:1277-88.

13. Mayring P. Qualitative content analysis. Forum: Qualitative Social Research, 2000;1(2) <http://217.160.35.246/fqs-texte/200/2-00mayring-e.pdf $>$ (Accessed August 14, 2013).

14. Sandelowski M. Whatever happened to qualitative description? Res Nurs Health 2000;23:334-40.

15. Miller WL, Crabtree BF. Primary care research: A multimethod typology and qualitative road map. In: Crabtree BF, Miller WL, eds. Doing Qualitative Research. Newbury Park, California: Sage, 1992:3-28.

16. Budassi-Sheehy S, Barber JM. Emergency Nursing: Principles and Practice, 3rd edn. London: Elsevier Health Sciences, 1992.

17. Registered Nurses' Assocation of Ontario (RNAO). Nursing best practice guideline: Assessment and management of pain. Revised edn, 2007. <http://rnao.ca/bpg/guidelines/assessment-andmanagement-pain> (Accessed August 14, 2013).

18. Melzack R. The McGill Pain Questionnaire: Major properties and scoring methods. Pain 1975;1:277-99.

19. Potter WJ, Levine-Donnerstein D. Rethinking validity and reliability in content analysis. J Appl Comm Res 1999;27:258-84.

20. Leininger $M$. Evaluation criteria and critque of qualitative research studies. In: Morse J, ed. Critical Issues in Qualitative Research Methods. Thousand Oaks: Sage, 1994:95-115.

21. Patton MQ. Qualitative research and evaluation methods, 3rd edn. Thousand Oaks: Sage, 2002.

22. Craig KD, Stanford EA, Fairbairn NS, Chambers CT. Emergent pain language communication competence in infants and children. Enfance 2006;58:52-71.

23. McGrath PJ. Annotation: Aspects of pain in children and adolescents. J Child Psychol Psychiatry 1995;36:717-30.

24. Stanford EA, Chambers CT, Craig KD. A normative analysis of the development of pain-related vocabulary in children. Pain 2005;114:278-84.

25. Melzack R, Torgerson WS. On the language of pain. Anesthesiology 1971;34:50-9.

26. Norvell KT, Gaston-Johansson F, Zimmerman L. Pain description by nurses and physicians. J Pain Symptom Manage 1990;5:11-7.

27. IASP Task Force on Taxonomy. Part III. Pain terms, a current list with definitons and notes on usage. In: Merskey H, Bogduk N, eds. Classification of Chronic Pain, 2nd edn. Seattle: IASP Press, 1994:209-14.

28. Fuller B. Meanings of discomfort and fussy-irritable in infant pain assessment. J Pediatr Health Care 1996;10:255-63.

29. Sweet SD, McGrath PJ. Physiological measures of pain. In: Finley GA, McGrath PJ, eds. Measurement of Pain in Infants and Children. Seattle: IASP Press; 1998:59-81.
30. Don N, McMahon C, Rossiter C. Effectiveness of an individualized multidisciplinary programme for managing unsettled infants. J Paediatr Child Health 2002;38:563-7.

31. Helseth S, Begnum S. A comprehensive definition of infant colic: Parents' and nurses' perspectives. J Clin Nurs 2002;11:672-80.

32. Soltis J. The signal functions of early infant crying. Behav Brain Sci 2004;27:443-58.

33. Keefe MR, Barbosa GA, Froese-Fretz A, Kotzer AM, Lobo M. An intervention program for families with irritable infants. MCN Am J Matern Child Nurs 2005;30:230-6.

34. Broome ME, Tanzillo H. Differentiating between pain and agitation in premature neonates. J Perinat Neonatal Nurs 1990;4:53-62.

35. Jones MA. Identifying signs that nurses interpret as indicating pain in newborns. Pediatr Nurs 1989;15:76-9.

36. McGrath PJ, Johnson G, Goodman JT, Schillinger J, Dunn J, Chapman J. CHEOPS: A behavioral scale for rating postoperative pain in children. In: Fields HL, ed. Advances in Pain Research and Therapy. New York: Raven Press, 1985:395-402.

37. Krechel SW, Bildner J. CRIES: A new neonatal postoperative pain measurement score. Initial testing of validity and reliability. Paediatr Anaesth 1995;5:53-61.

38. Merkel SI, Voepel-Lewis T, Shayevitz JR, Malviya S. The FLACC: A behavioral scale for scoring postoperative pain in young children. Pediatr Nurs 1997;23:293-7.

39. Stevens B, McGrath P, Yamada J, et al. Identification of pain indicators for infants at risk for neurological impairment: A Delphi consensus study. BMC Pediatr 2006;6:1.

40. Stevens B, Johnston C, Petryshen P, Taddio A. Premature Infant Pain Profile: Development and initial validation. Clin J Pain 1996;12:13-22.

41. Ash, JS, Berg M, Coiera E. Some unintended consequences of information technology in health care: The nature of patient care information system-related errors. J Am Med Inform Assoc 2004;11:104-112.

42. Wenger E. Communities of Practice: Learning, Meaning, and Identity. Cambridge: Cambridge University Press, 1998.

43. Keele KD. The pain chart. Lancet 1948;2:6-8.

44. Kortesluoma R, Nikkonen M. 'The most disgusting ever': Children's pain descriptions and views of the purpose of pain. J Child Health Care 2006;10:213-27.

45. Azize PM, Humphreys A, Cattani A. The impact of language on the expression and assessment of pain in children. Intensive Crit Care Nurs 2011;27:235-43.

46. Cleeland CS, Ryan KM. Pain assessment: Global use of the Brief Pain Inventory. Ann Acad Med Singapore 1994;23:129-38.

47. Dallenback KM. Somesthesis. In: Barring EG, Lanfield HS, Weld HP, eds. Introduction to Psychology. New York: John Wiley, 1939:608-25.

48. von Baeyer C. What's the score in pain assessment? Med J Aust 2012;96:379. 


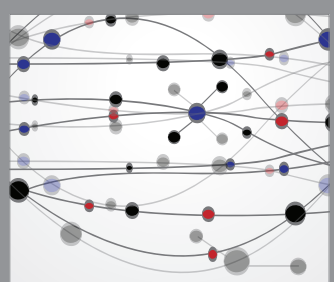

The Scientific World Journal
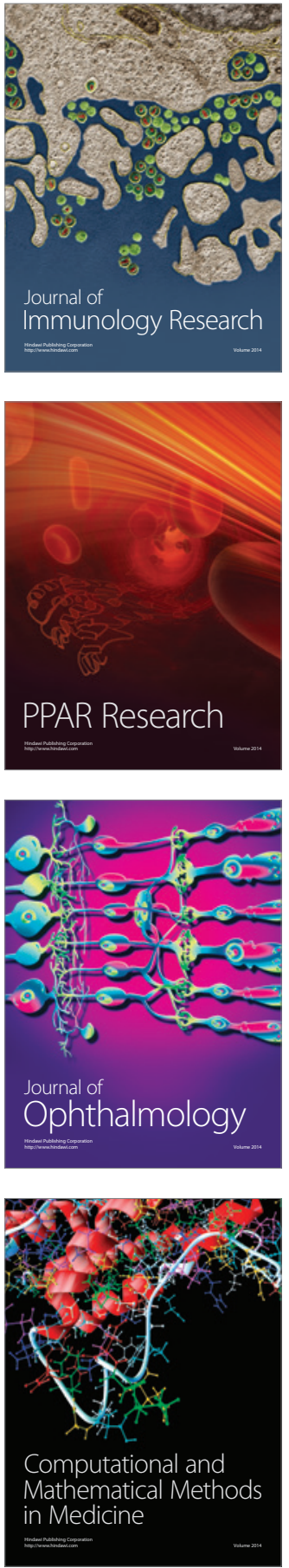

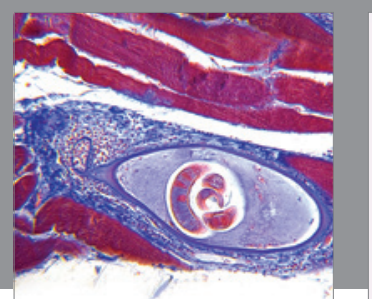

Gastroenterology Research and Practice

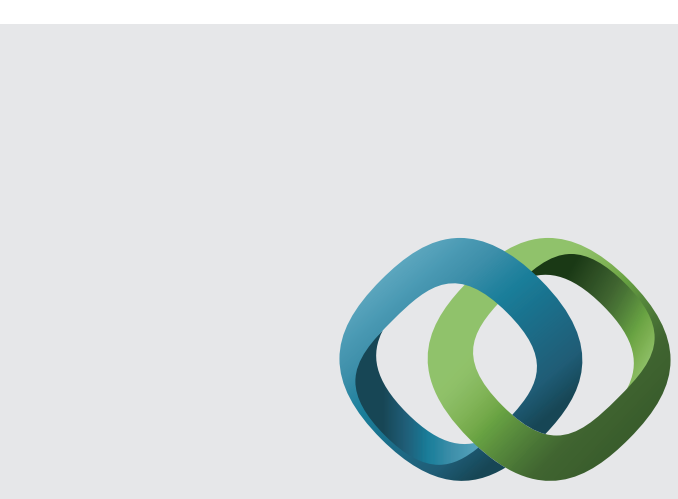

\section{Hindawi}

Submit your manuscripts at

http://www.hindawi.com
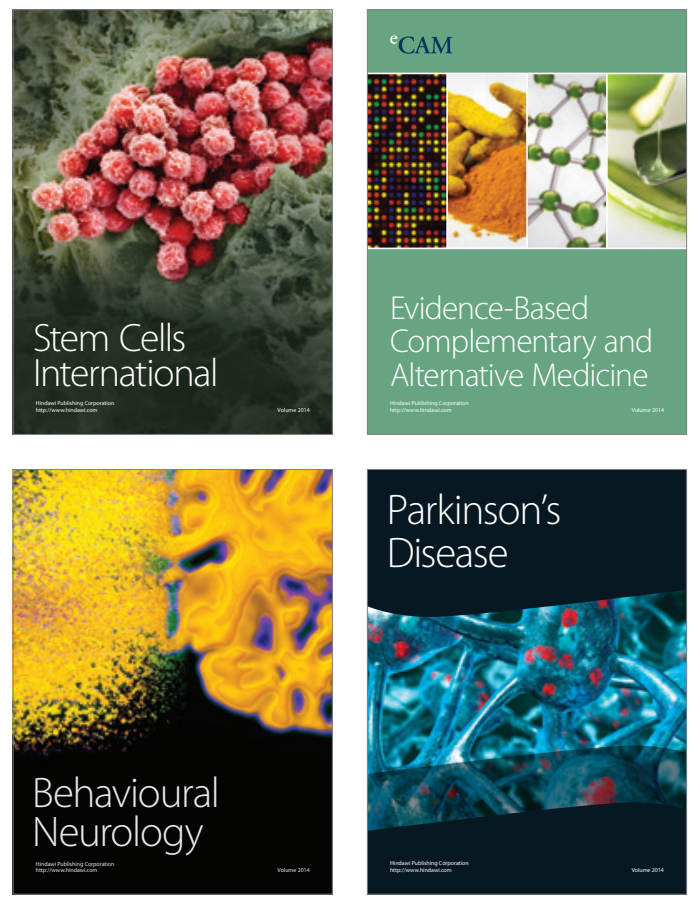
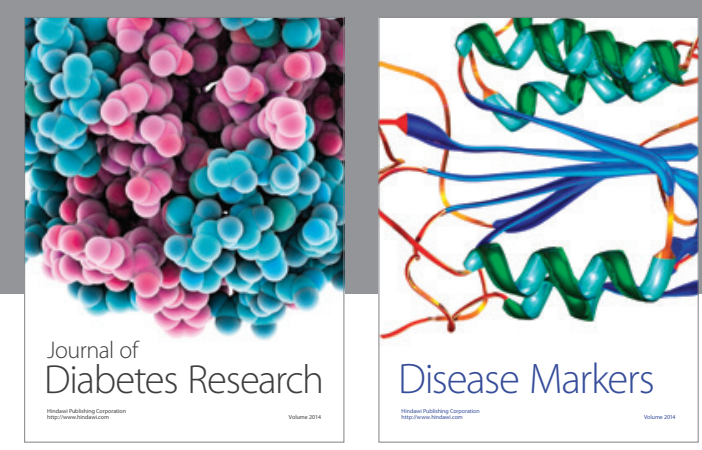

Disease Markers
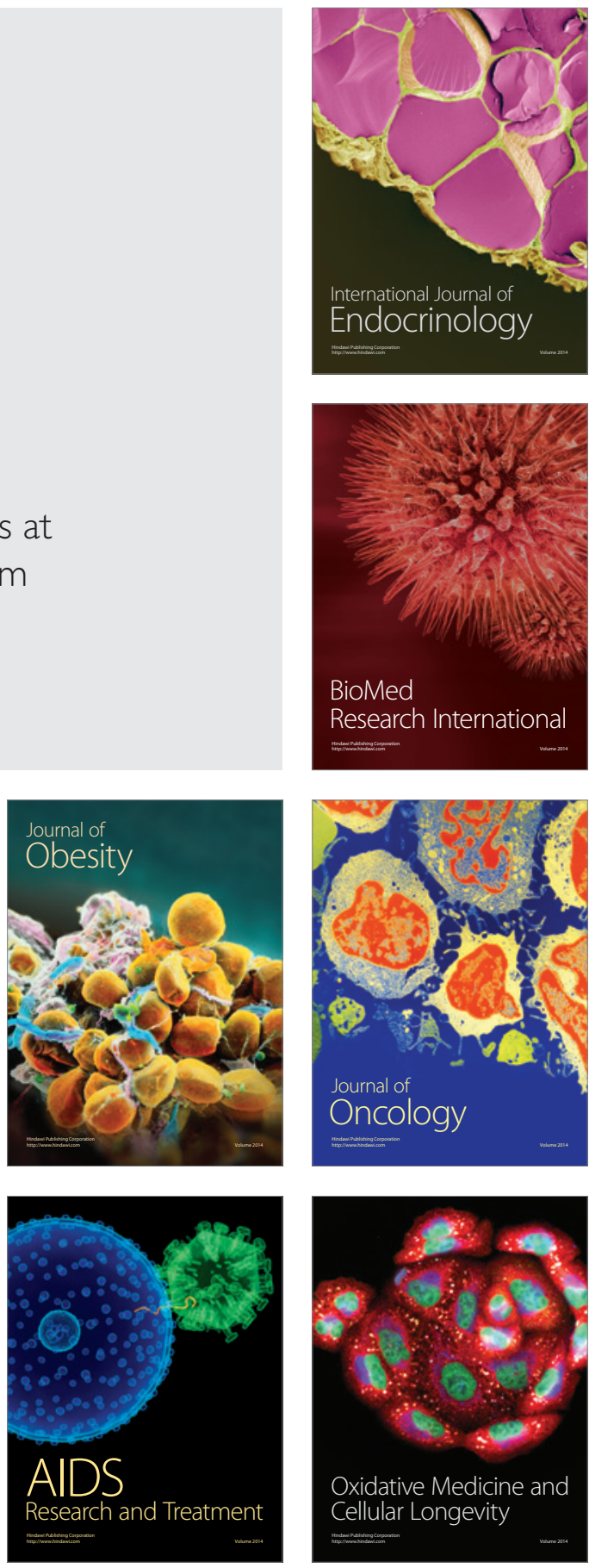